\section{Unlocking materials opportunities in manufacturing}

\author{
http://manufacturing.gov/nnmi.html
}

O August 1st, the final day of the legislative session before the long August recess, Congress introduced the "Revitalize American Manufacturing Act of 2013." A rare bipartisan, bicameral effort to establish the United States as the leader in next-generation advanced manufacturing, the Act represents a new policy approach to integrating applied research, product development, and commercialization.

The bill itself is relatively modest; it seeks to accelerate commercialization of new technologies through the creation of a National Network for Manufacturing Innovation (NNMI). This Network would be comprised of a number of joint public-private regional centers, focusing on industry-chosen emerging technologies.

However, the core ideas contained in the proposal strike at the heart of the debate over the role of publically funded research - with profound implications for scientific researchers - and materials science stands to be one of the prime beneficiaries.

Recently, President Obama announced the creation of three new institutes. Two of these three institutes fall squarely within applied materials science: the Lightweight and Modern Metals Innovation center, supported by the Department of Defense, and the Clean Energy Manufacturing Innovation institute for wide-bandgap semiconductors, supported by the Department of Energy, will provide new opportunities and avenues for collaborations for materials researchers.

These institutes will become part of NNMI once established by Congress. The bill would also establish a National Program Office headquartered at the National Institute of Standards and Technology to tie the regional centers together, sharing best practices and approaches to handling intellectual property.

The centers themselves and the broader philosophy contained in the NNMI ap- proach means much more than increased research dollars. NNMI seeks to bring together researchers, businesses, educators, manufacturers, and financiers under a single roof. Next-generation technologies will be developed, scaled to production, and commercialized in parallel with workforce development. The federal role of risk-sharing and pooling resources will allow breakthrough platform technologies to develop, while private innovation will drive market-specific applications.

This policy is a response to questions over what motivates innovation, and once it occurs, how the value-added in manufacturing and production is captured. On one hand, federal support for basic and applied research in the United States over the past century has led to the development of revolutionary technologies in agriculture, medicine, and nanotechnology, among other fields. However, according to the Obama administration, the United States has experienced an "invent here, produce there" problem in sustaining industries that are spawned from taxpayer-funded research and development (R\&D).

Innovation is a primary driver of economic growth, yet it is difficult to generate and even harder to predict. Even direct R\&D spending, either public or private, is no guarantee that meaningful innovation will occur. The best that can be done is to facilitate communication and create feedback loops across researchers, engineers, and manufacturers; ensure access to a developed, skilled workforce; establish confidence that regional assets will be in place long term; create a clear regulatory structure for emerging technologies; and provide capital and expertise to those technologies most likely to succeed. Businesses are increasingly seeking environments that provide these comprehensive "ecosystems."

This is precisely what NNMI does, and at a cost much lower than traditional levels of R\&D investment.

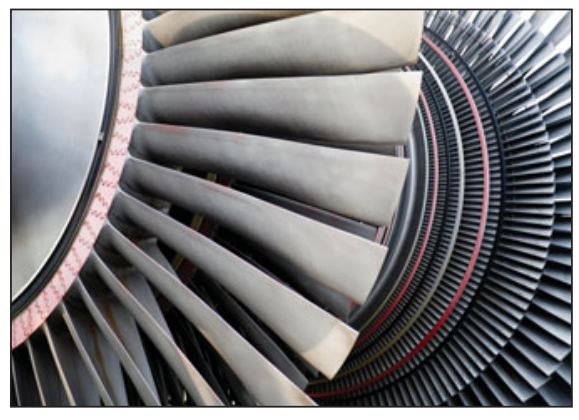

Turbines for power generation have complex, precise geometries, and are manufactured using difficult-to-machine high-temperature alloys.

So what does this mean for materials researchers? First, more dollars will be available for research. However, in contrast to broad agency-awarded grants, the money will be closely tied to precompetitive technologies with clear market applications. Second, researchers will have an increased opportunity to engage with private industry, which will have significant spillover benefits in the form of patents and spin-off ventures. Finally, students will have the ability to carry their research out of the laboratory through the development process within a controlled environment, getting realworld entrepreneurial experience.

The breadth of the discipline means that materials science and engineering will necessarily be involved in many, if not all, of the institutes within the NNMI. Proposed topics include energy storage, amorphous metals manufacturing, nanobiotechnology, flexible electronics, forming and joining technologies, supply chain automation, and photonics and integrated photonic circuits, among others. Opportunity abounds for materials researchers within the NNMI structure.

In order to unlock these tremendous opportunities for students, scientists, private industry, and overall US competitiveness, Congress needs to take up and pass the "Revitalize American Manufacturing Act of 2013" during the fall legislative sessions.

Andrew Steigerwald 2012-2013 Materials Research Society/The Minerals, Metals and Materials Society Congressional Science and Engineering Fellow 